\title{
Central hypoventilation with PHOX2B expansion mutation presenting in adulthood
}

\author{
S Barratt, A H Kendrick, F Buchanan, A T Whittle
}

Thorax 2007;62:919-920. doi: 10.1136/thx.2006.068908

Congenital central hypoventilation syndrome most commonly presents in neonates with sleep related hypoventilation; late onset cases have occurred up to the age of 10 years. It is associated with mutations in the PHOX2B gene, encoding a transcription factor involved in autonomic nervous system development. The case history is described of an adult who presented with chronic respiratory failure due to PHOX2B mutation-associated central hypoventilation and an impaired response to hypercapnia.

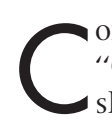
ongenital central hypoventilation syndrome (CCHS, "Ondine's Curse") classically presents in neonates with sleep-dependent hypoventilation. Affected infants have an impaired ventilatory response to hypercapnia and hypoxaemia which is not caused by other identifiable disease. ${ }^{1}$ CCHS has associations with Hirschsprung disease, neural crest tumours and abnormalities of autonomic nervous system (ANS) control. ${ }^{1-3}$

The PHOX2B gene encodes a transcription factor involved in neural crest differentiation and hence ANS and central respiratory control system development. ${ }^{45}$ Amiel et al identified PHOX2B mutations in 18 of 29 infants with CCHS, most commonly an expansion of a 20-residue polyalanine encoding sequence by an additional 5-9 alanine encoding triplets. ${ }^{4}$

A subset of children with CCHS and PHOX2B mutations present after the neonatal period, with new diagnoses reported up to the age of 10 years described as late onset central hypoventilation syndrome (LOCHS). ${ }^{6-8}$ There has been one reported case of adult onset where the father of two girls with LOCHS developed respiratory failure acutely following surgery for sleep apnoea and was found to have a PHOX2B mutation identical to his daughters. ${ }^{9}$

\section{CASE REPORT}

A 41-year-old man was admitted in 2005 complaining of ankle swelling, morning headaches, low mood and hypersomnolence for 2 months. In 1996 he had required mechanical ventilation for community acquired pneumonia and had been slow to wean from ventilation with poor respiratory effort. Oxygen desaturation at sleep onset was noted during the acute illness. No abnormality was found at respiratory and neurological outpatient reviews in 1997. In 2003 he was seen in the cardiology clinic with ankle oedema which was ascribed to gout following a normal cardiorespiratory assessment.

He had never smoked but had a history of alcohol consumption estimated at 80 units per week in 1996 and 70 units per week in 2005. Furosemide $80 \mathrm{mg}$ daily had been prescribed 1 month before admission. He worked as a civil servant, was single with no children, and had no family history of respiratory disease, hypoventilation or ANS disease.

His body mass index was $35 \mathrm{~kg} / \mathrm{m}^{2}$. He was drowsy, confused and had oedema to the mid thigh. Physical examination was otherwise unremarkable. An anteroposterior chest radiograph suggested cardiac enlargement and an ECG showed right heart strain. Oxygen saturation by pulse oximetry $\left(\mathrm{Spo}_{2}\right)$ on air was $80 \%$ and arterial blood gas analysis on $24 \%$ fractional inspired oxygen showed hypercapnic respiratory failure ( $\mathrm{pH} 7.21$, oxygen tension $8.6 \mathrm{kPa}$, carbon dioxide tension $10.3 \mathrm{kPa}$ ). He was polycythaemic with haematocrit $64 \%$. He was treated with antibiotics, diuretics, controlled oxygen therapy and face mask non-invasive positive pressure ventilation (NIV).

From day 2 his daytime oxygenation was satisfactory on low flow oxygen without ventilatory support; he remained on nocturnal NIV. Two attempts to record overnight oximetry without ventilatory support failed: his $\mathrm{SpO}_{2}$ fell below 50\% due to apnoea within 30 min of sleep onset and the nursing staff recommenced NIV on each occasion. Overnight oximetry on air with auto-adjusting continuous positive airway pressure (AutoCPAP; REMSTAR-Auto, Respironics, Murrysville, Penn, USA) showed episodes of profound desaturation with a mean $\mathrm{SpO}_{2}$ of $84 \%$ and a nadir of $45 \%$. On air with NIV the mean $\mathrm{SpO}_{2}$ was $94 \%$ with a nadir of $89 \%$ (fig 1 ). From this response to NIV compared with the response to auto-CPAP, we concluded that his apnoeic episodes were primarily central rather than obstructive.

He was investigated for neuromuscular causes of hypoventilation. Maximal respiratory mouth pressure measurement was within normal limits, showing $+77 \mathrm{~cm} \mathrm{H}_{2} \mathrm{O}$ in expiration and $-63 \mathrm{~cm} \mathrm{H}_{2} \mathrm{O}$ in inspiration. Cranial MRI, nerve conduction, electromyogram and edrophonium testing were normal. A borderline increase in acetylcholine receptor antibodies was found on one occasion but a repeat assay was negative. An echocardiogram was normal.

He was discharged after 23 days with domiciliary nocturnal pressure controlled NIV with assured minimum tidal volume of $500 \mathrm{ml}$ (Synchrony AVAPS, Respironics). His oedema had resolved and awake $\mathrm{SpO}_{2}$ on air was $97 \%$. On review at 6 months he was asymptomatic and physical examination was normal. Spirometric tests showed a mildly restrictive pattern in keeping with his body habitus, with forced expiratory volume in $1 \mathrm{~s}$ of 2.8 litres $(72 \%$ predicted) and a ratio of forced expiratory volume in $1 \mathrm{~s}$ to forced vital capacity of $84 \%$. The data recorded by his NIV device, averaged over 6 months, showed that $31 \%$ of the breaths delivered had been triggered by his respiratory effort. This compares with $>90 \%$ seen in our patients on domiciliary NIV without central hypoventilation.

Physiological assessment of his responses to hypercapnia when clinically stable showed a ventilatory increment of $0.07 \mathrm{l} /$ $\mathrm{min} / \mathrm{kPa}$ carbon dioxide tension using Read's carbon dioxide rebreathing method (normal $0.15-0.83)^{10}$ and a mouth occlusion pressure at $100 \mathrm{~ms}$ (a marker of respiratory drive $)^{11}$ increment of $0.061 \mathrm{~cm} \mathrm{H}_{2} \mathrm{O} / \mathrm{mm} \mathrm{Hg}$ carbon dioxide tension (normal 0.52 (SD 0.19)). ${ }^{12}$ Genetic analysis by the Bristol

Abbreviations: ANS, autonomic nervous system; $\mathrm{CCHS}$, congenital central hypoventilation syndrome; LOCHS, late onset central hypoventilation syndrome; NIV, non-invasive ventilation; $\mathrm{SpO}_{2}$, oxygen saturation 


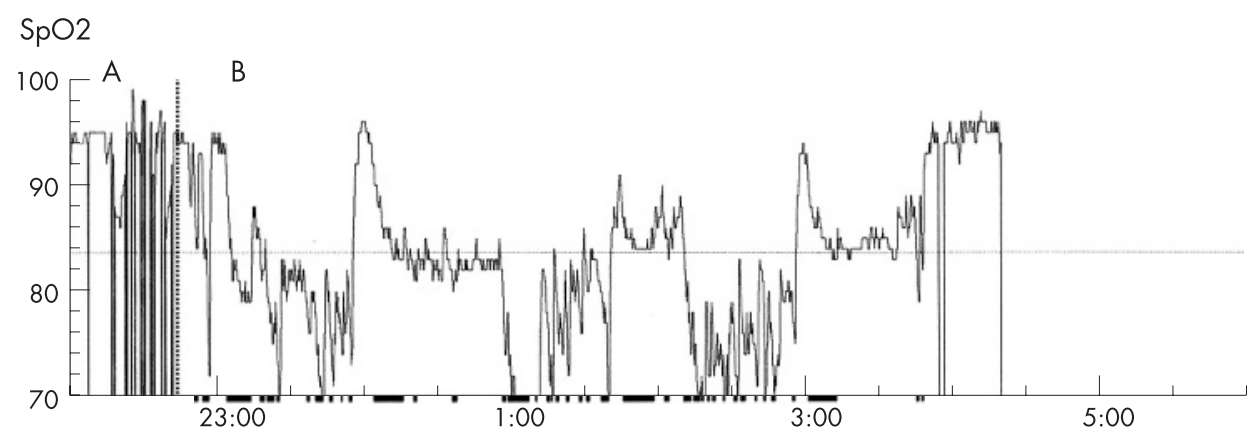

Figure 1 Recordings of overnight oxygen saturation $\left(\mathrm{SpO}_{2}\right)$ on air: $A$, artefact; $B$, autocontinuous positive airway pressure; $C$, no respiratory support; $D$, artefact; $E$, noninvasive positive pressure ventilation (inspiratory positive airway pressure 20, expiratory positive airway pressure 6).

$\mathrm{SpO} 2$

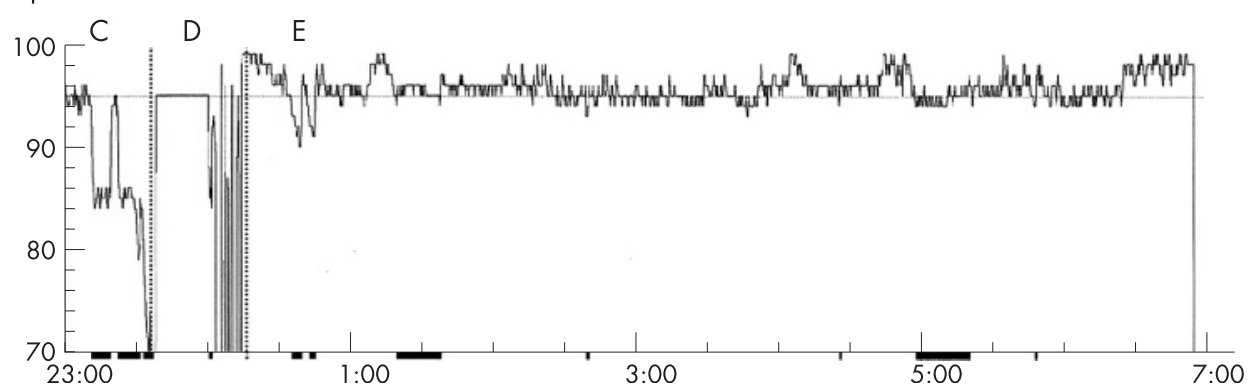

Clinical Genetics Department using GC-rich PCR and expansion sizing on a Beckman Coulter analyser showed a heterozygous five alanine expansion mutation of the 20-residue polyalanine tract in exon 3 of the PHOX2B gene.

\section{DISCUSSION}

We report a case of CCHS associated with PHOX2B mutation presenting with chronic respiratory failure in adulthood, with quantified impairment of the response to hypercapnia.

In retrospect, our patient showed evidence of reduced respiratory drive and sleep related hypoventilation during his pneumonia in 1996 at the age of 32 years. He was then asymptomatic until he developed oedema at the age of 39 . When admitted at 41 years of age he had chronic respiratory failure and profound nocturnal hypoventilation. His moderate obesity and alcohol consumption did not seem sufficient explanation for this degree of hypoventilation, and no other cause was identified until we found the genetic abnormality characteristic of childhood CCHS.

The size of the PHOX2B polyalanine expansion mutation in children with CCHS varies from 5 to 13 nucleotide triplets; larger numbers of copies are associated with more severe hypoventilation and other features of neural crest maldifferentiation. ${ }^{6}{ }^{13}$ Both our subject and the other reported adult onset case had five expansion copies, supporting the hypothesis that smaller copy numbers are associated with later presentation of hypoventilation. ${ }^{6}{ }^{9}$ The spectrum of CCHS associated with PHOX2B mutation can now be extended to include sleep related hypoventilation causing respiratory failure presenting in adulthood.

\section{ACKNOWLEDGEMENTS}

The authors thank the subject, who has consented to publication of his clinical details, and Dr Peter Lunt and the Bristol Genetics Laboratories, Southmead Hospital, Bristol.

\section{Authors' affiliations}

S Barratt, A H Kendrick, F Buchanan, A T Whittle, Department of Respiratory Medicine, Bristol Royal Infirmary, Bristol, UK
Funding: None

Competing interests: None

Correspondence to: $\operatorname{Dr}$ A T Whittle, Department of Respiratory Medicine, Bristol Royal Infirmary, Bristol BS2 8HW, UK; adam.whittle@ubht.nhs.uk

Received 8 September 2006

Accepted 13 December 2006

\section{REFERENCES}

1 Weese-Mayer DE, Shannon DC, Keens TG, et al. American Thoracic Society. Idiopathic congenital central hypoventilation syndrome: diagnosis and management. Am J Respir Crit Care Med 1999;160:368-73.

2 Trang H, Boureghda S, Denjoy I, et al. 24-hour BP in children with congenital central hypoventilation syndrome. Chest 2003;124:1393-9.

3 Faure C, Viarme F, Cargill G, et al. Abnormal oesophageal motility in children with congenital central hypoventilation syndrome. Gastroenterology 2002;122:1258-63.

4 Amiel J, Laudier B, Attie-Bitach T, et al. Polyalanine expansion and frameshift mutations of the paired like homeobox gene Phox $2 \mathrm{~b}$ in congenital central hypoventilation syndrome. Nat Genet 2003;33:459-61.

5 Dauger S, Pattyn A, Lofaso F, et al. Phox $2 b$ controls the development of peripheral chemoreceptors and afferent visceral pathways. Development 2003;130:6635-42.

6 Matera I, Bachetti T, Puppo F, et al. Phox $2 b$ mutations and polyalanine expansions correlate with the severity of the respiratory phenotype and associated symptoms in both congenital and late onset central hypoventilation. J Med Genet 2004;41:373-80.

7 Katz ES, McGrath S, Marcus CL. Late-onset central hypoventilation with hypothalamic dysfunction: a distinct clinical syndrome. Pediatr Pulmonol 2000;29:62-8.

8 Gothi D, Joshi JM. Late onset hypoventilation syndrome: is there a spectrum of idiopathic hypoventilation syndromes? Indian J Chest Dis Allied Sci 2005;47:293-8.

9 Weese-Mayer DE, Berry-Kravis EM, Zhou L. Adult identified with congenital central hypoventilation syndrome - mutation in Phox $2 \mathrm{~b}$ gene and late-onset $\mathrm{CHS}$ Am J Respir Crit Care Med 2005;171:88.

10 Read DJC. A clinical method of assessing ventilatory response to carbon dioxide. Australas Ann Med 1967; 16:20-32.

11 Whitelaw WA, Derenne J, Millic-Emili J. Occlusion pressure as a measure of respiratory centre output in conscious man. Respir Physiol 1975;23:181-99.

12 Gelb AF, Klien E, Sciffman P, et al. Ventilatory response and drive in acute and chronic obstructive pulmonary disease. Am Rev Respir Dis 1977;1 16:9-16.

13 Trochet D, O'Brien LM, Gozal D, et al. Phox $2 b$ genotype allows for prediction of tumour risk in congenital central hypoventilation syndrome. Am J Hum Genet 2005;76:421-6. 